\title{
Development of Endangered Animals' Surveillance System
}

\author{
Phesto Peter Namayala \\ Department of Information and Communication Technology \\ Mbeya University of Science and Technology \\ Box 131, Mbeya, Tanzania
}

\begin{abstract}
In Tanzania, the real-time endangered animal health monitoring system has been a challenge and there has been speculation that many wild animals are dying because of not being attended in time when they get sick. The matter is even worse to younger elephants.

In recent years various bio-sensors for animal health management have been invented and developed and some of them are ready for commercialization, among others antibiotic detection, microfluidics, fluoresce resonance energy transfer (FRET), quantum dots, surface Plasmon resonance technology (SPR) and hybrid technology are widely used. However, there is a need for integrating all the available sensors and create an efficient online monitoring system so that animal health status can be monitored in real-time without delay.

To furnish this research and integrate components to create a real-time online monitoring system we used both qualitative and quantitative research design, questionnaires with a closed-ended question were used for data collection and finally SPSS was applied when analyzing data to present findings.

The research ended with the development of a prototype which may help gamekeeper to online monitor health parameters and elephants' location whenever there is an abnormal situation.
\end{abstract}

.Key Words: Health, Endangered Animals, Real time monitoring, Elephants, Management

\section{INTRODUCTION}

\subsection{Situational analysis}

Elephant population in African countries is enduring shirking daily, among other issues, depopulation has been found to mainly be caused by longevity, predators, diseases, human impacts, poaching for ivory, poaching repercussions habitat loss, crop damage, contaminated Water Sources, culling and large game trophy hunts [1]. TANAPA has prioritizes 13 research areas identified in the Tanzania National Parks where Monitoring of animal population-ecology including rare, endemic and keystone species of different taxa as indicators of ecosystem health is one of them. In this category Assessment of the effect of baboon genital disease on their population dynamics and ability to reproduce effectively, Map disease vectors species (tsetse flies, ticks, etc) and their distribution, Investigate causes and epidemiology of the Giraffe skin disease and Prevalence of important diseases (rabies, anthrax, rift valley fever, tuberculosis and brucellosis) in wildlife and domestic animals have been given different priorities [2].Various researches interventions have been made on poaching and human elephant's conflicts, but little has been done on diseases leaving us with diminutive or no evidences to report on the enormousness of the problem statistically. Based on the work of Dr Shelton Atapattu elephants are susceptible to a number of diseases comprising rabies, tetanus, anthrax and other infectious diseases including tuberculosis, hemorrhagic septicemia, trypanosomiasis, pyroplasmosis, foot and mouth disease, pox, bacillary necrosis, salmonellosis, streptococcus's, babesiosis, helminthiasis and ectoparasitism [3]. At SELOUS GAME RESERVE of Tanzania traditional approaches are still used by Gamekeepers to protect elephants from poachers and diseases attack, among others moving around the wildlife habitat and settlement not daily but at certain period of time i.e. one day per week has been a common practice [4]. However it has remained a challenge to ensure a real time monitoring of wildlife's health status including that of elephant and offer mandatory veterinary supports before it is too late. Among others Inadequate funds for wildlife diseases surveillance, Inadequate equipment/facilities for surveillance, Inadequate laboratory diagnostic capacity, Inadequate wildlife veterinary staff, Limited communication between focal points and the National OIE delegates, High turnover of National OIE delegates and focal points and Limited access/failure to report via the WAHIS interface for notification of disease occurrence in wildlife have been acknowledged as the foremost challenges. 


\subsection{Problem statement}

From the data provided by the Tanzania Wildlife Research Institute (TAWIRI), the problem of death of Tanzanian animals where elephants are not exceptional has rapidly been increasing from 1990s to date. For example in 2011 the total world populations of elephants was about 423,000 down from 1.3 million in 1979. In 1994 Tanzania had an elephant population of about 355,000 but this number dropped promptly to 180,000 in 1999 and even less than that in 2011.TAWIRI prompted that Tanzania is losing about 30 elephants daily due to poaching problem. Though many researchers are identifying poaching as the major cause of elephant's mortality we cannot ignore diseases. The situation on the ground tells that the remaining elephants are in danger of being completely wiped out if urgent measures are not taken [4].

Wild animal including elephant surveillance is in itself a challenge, given the scarcity of data on wildlife population distribution, abundance, behaviour, or health status and the difficulties in collecting and interpreting wildlife surveillance information. New developments in companion animal surveillance and in the sourcing and analysis of surveillance data across other populations and sectors have emerged, aiming at a more integrated approach [5].

The emphasis of this research work is to come up with an elephant's surveillance system that will remotely be used to monitor elephant's health parameters and provide real time data of body temperature and heart beats when there is an abnormalities, The research assumes the abnormalities to be caused by either diseases, predators, and poachers, collected data together with the animal location will automatically be sent to the game reserve's information centre using SMS's based technology. With the help of other available technologies like Google maps and other positioning technologies gamekeepers will be able to locate and reach the elephant with glitch and provide indispensable veterinary supports. The developed system will also provide elasticities which allow gamekeepers to send an ad hoc query soliciting required information from anywhere anytime.

Together with other existing systems, this system will help gamekeeper while tracking elephant's location and monitor health status parameters mainly heart beat and body temperature. By doing so the system is expected to reduce death of elephants due to tropical diseases.

\section{BACKGROUND STUDY}

\subsection{Literature Review}

In this research of developing endangered animal's surveillance system, the development is cantered by the Microcontroller which receives and manipulates captured data from both temperature sensor, heart beat sensor and a GPS module. Temperature sensor collects animal's temperature data, the heart beat sensor collects animal's heart beats and the GPS module collects the current animal's waypoint, collected data are fed to the microcontroller which decides when to send them to the keeper's information centre. The microcontroller has been configured to send data when collected readings are abnormal, the table below shows both minimum and maximum elephant's temperature and heart beats.

Table 1: Elephant's heart beats (Source: Proceedings of the American Philosophical Society, Vol. 76, No. 3 (1936), pp. 335 341)

\begin{tabular}{|l|l|l|}
\hline \multirow{2}{*}{ Animal } & \multicolumn{2}{|c|}{ Heart beats } \\
\cline { 2 - 3 } & Minimum & Maximum \\
\hline Elephant & 23 beats per minute & 39 beats per minute \\
\hline
\end{tabular}

Table 2: Elephant's body temperature (Source: Proceedings of the National Academy of Sciences of the United States of America, Vol. 22, No. 6 (Jun. 15, 1936), pp. 405-408

\begin{tabular}{|l|c|c|}
\hline \multirow{2}{*}{ Animal } & \multicolumn{2}{|c|}{ Body temperature } \\
\cline { 2 - 3 } & Minimum $\left({ }^{\circ} \mathrm{C}\right)$ & Maximum $\left({ }^{\circ} \mathrm{C}\right)$ \\
\hline Elephant & 35.4 & 36.3 \\
\hline
\end{tabular}

Wildlife disease surveillance can be a useful and complementary component of human and animal disease surveillance, monitoring, prevention and control programmes, as well as conservation efforts. In the context of animal health, wildlife disease surveillance may provide information of domestic and wild animal morbidity and mortality, identify changes in patterns of disease occurrence over time, and assist in early detection of disease outbreaks, including those linked to emerging diseases. Core components of wildlife diseases surveillance include Detection of pathogens and diseases, Identification of pathogens and diseases, Analysis and communication and Information Management [6]. Diseases, when expressed in free-ranging animals, can have a significant effect on wildlife ecologies. Whilst some diseases exist as symptomless, subclinical infections without any obvious ecological impact and of no consequence for domestic animals or humans, occasionally there are dramatic epizootic outbreaks characterised by high morbidity and mortality [7]. 
In recent years various bio-sensors for animal health management have been invented and developed and some of them are ready for commercialization, among others antibiotic detection, micro fluidics, fluoresce resonance energy transfer (FRET), quantum dots, surface Plasmon resonance technology (SPR) and hybrid technology are widely used. However there is a need of integrating all the available sensors and create an efficient online monitoring system so that animal health status can be monitored in real time without delay [8]. Researchers are now working on PLF as a means of increasing animal productivity, improve animal welfare and health, whilst reducing environmental impact. The improvement of animal productivity is achieved using real time monitoring and management systems, alerting the farmer instantly when problems arise. The same mechanisms of PLF in a long run can be extended to wild animals including elephants and provide the same benefits, as a new and upcoming technology that have the potential to revolutionise the livestock farming industries, PLF or Smart Farming if properly implemented could improve or at least objectively document animal welfare on farms [9]. In Tanzania Mikumi National park we were we conducted our research, it has been identified that there is no formal system used for animals' health monitoring. Frequency distributions tables below shows responses from game keepers per question asked.

\begin{tabular}{|c|c|c|c|c|c|}
\hline & & Frequency & Percent & Valid Percent & Cumulative Percent \\
\hline \multirow{4}{*}{ Valid } & Physical health checkups & 64 & 69.6 & 69.6 & 69.6 \\
\hline & Don't have any means & 11 & 12.0 & 12.0 & 81.5 \\
\hline & Not sure & 17 & 18.5 & 18.5 & 100.0 \\
\hline & Total & 92 & 100.0 & 100.0 & \\
\hline
\end{tabular}

Table 3: What means do you normally use to monitor and detect an elephant's health status (i.e. diseases) at game reserves?

\begin{tabular}{|ll|r|r|r|r|}
\hline & Frequency & Percent & Valid Percent & Cumulative Percent \\
\hline \multirow{4}{*}{ Valid } & Observing elephants & 49 & 53.3 & 53.3 & 53.3 \\
& Being notified by tourist & 43 & 46.7 & 46.7 & 100.0 \\
& Total & 92 & 100.0 & 100.0 & \\
\hline
\end{tabular}

Table 4: According to your experience which way(s) do you use to know if certain elephant is sick in a game reserve?

\begin{tabular}{|c|c|c|c|c|c|}
\hline & & Frequency & Percent & Valid Percent & Cumulative Percent \\
\hline \multirow{3}{*}{ Valid } & YES & 59 & 64.1 & 64.1 & 64.1 \\
\hline & NO & 33 & 35.9 & 35.9 & 100.0 \\
\hline & Total & 92 & 100.0 & 100.0 & \\
\hline
\end{tabular}

Table 5: Are there any specific means of identifying the specific elephants' location in the reserve? 


\begin{tabular}{|ll|r|r|r|r|}
\hline & Frequency & Percent & Valid Percent & Cumulative Percent \\
\hline \multirow{4}{*}{ Valid } & 12 & 13.0 & 13.0 & 13.0 \\
& Less than a day & 44 & 47.8 & 47.8 & 60.9 \\
& One to three days & 36 & 39.1 & 39.1 & 100.0 \\
\cline { 2 - 5 } & Above three days & 92 & 100.0 & 100.0 & \\
Total & &
\end{tabular}

Table 6: In average how long does it takes to know if a certain elephant's sick?

\begin{tabular}{|c|c|c|c|c|c|}
\hline & & Frequency & Percent & Valid Percent & Cumulative Percent \\
\hline \multirow{4}{*}{ Valid } & Diseases & 44 & 47.8 & 47.8 & 47.8 \\
\hline & Human and elephant conflict & 22 & 23.9 & 23.9 & 71.7 \\
\hline & Poaching & 26 & 28.3 & 28.3 & 100.0 \\
\hline & Total & 92 & 100.0 & 100.0 & \\
\hline
\end{tabular}

\subsection{Research Significance}

Research is perfectly implemented and is anticipated to reduce Elephant's mortality, via monitoring health and determine their location for an instant elephant's doctor's interventions. The system also supports in dealing with poachers and predators through animal's engagements and behaviour's monitoring. The system is functioning automatically and does not need any human intervention implicating time and money saving. Development of this system has also been possible through the aid of computers technologies and state of the art high quality sensors acceptable to deliver the highest level of precisions. The system is enabled by SMS's technology while receiving and sending messages through affordable and extensively spread GSM technology.

\section{RESEARCH OBJECTIVES}

\subsection{Main Objective}

To develop an endangered animal's Surveillance System.

\section{2: Specific Objectives}

i. To design a system circuit.

ii. To simulate the system.

iii. To interface microcontroller with other components.

iv. To Program microcontroller.

v. To test the system

vi. To develop system documentation.

vii. To develop user documentation

\section{2: Research Scope and Limitations}

This research is narrowed to only afford monitoring of elephant's health status and communicate back both the current elephant's temperature, heart beats and waypoint by means of GSM network when atypical readings are apprehended. The readings may be a result of animal's sickness or behaviour and it will be the responsibilities of animal's experts to extinguish and provide necessary 
measures. Furthermore the research has been possible through reviewing various documents of previous researches in the same domain and collecting primary data from Mikumi National park. The research is assuming the same situation to prevail in other Tanzanian parks and other reserves.

\section{METHODOLOGY}

To complete the this research, both qualitative and quantitative design methods were used, the use of different design methods was targeting at complementing flaws of the two methods, simple random sampling technique was applied to sample respondents at Mikumi National park, Questionnaire with a closed ended questions was used when collecting data and finally SPSS was used to analyse data and present the findings

\subsection{Endangered animal's surveillance System design}

To explicitly enlighten the system's structure, behaviour and interaction with external actors various design methodologies were deployed. Following nature of the project block diagram was opted when communicating the system structure instead of the commonly used class diagrams and use case and sequence diagrams from Object Oriented design methodologies have been used to communicate interactions with external entities and system's behaviour. The detailed description of each system diagram is as shown below

\subsubsection{Block diagram of the developed system}

A block diagram is a specialized, high-level flowchart used in engineering. It is used to design new systems or to describe and improve existing ones. Its structure provides a high-level overview of major system components, key process participants, and important working relationships. Block diagrams usually provide a graphical representation of a system, they also used to provide a functional view of a system while focusing on the input and output of a system. The figure 1 below presents the block diagram for a developed system.

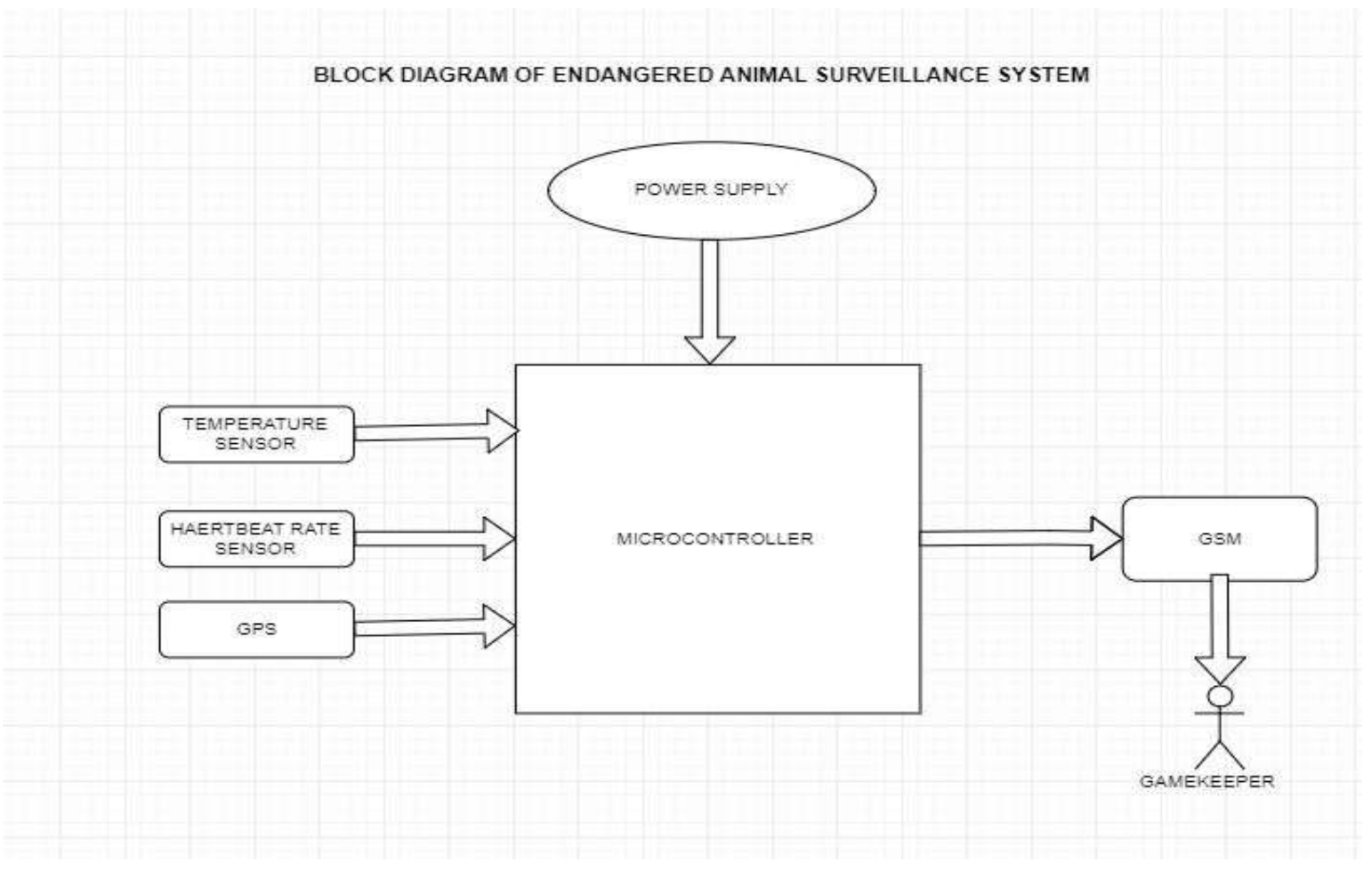

Figure 1: Block diagram of endangered animals' surveillance system

\subsubsection{Use case diagram}

Use Case Diagrams are usually referred as behaviour diagrams and are normally used to describe main system functions from the standpoint of an external observer, they emphasize on what the system does rather than how, they are created during the early 
stages of a project that is during the analysis phase rather than during the design phase, are used to provide a high-level view of what the system does and who uses it and finally are used as the ground when determining the user interfaces (UIs) to the system.

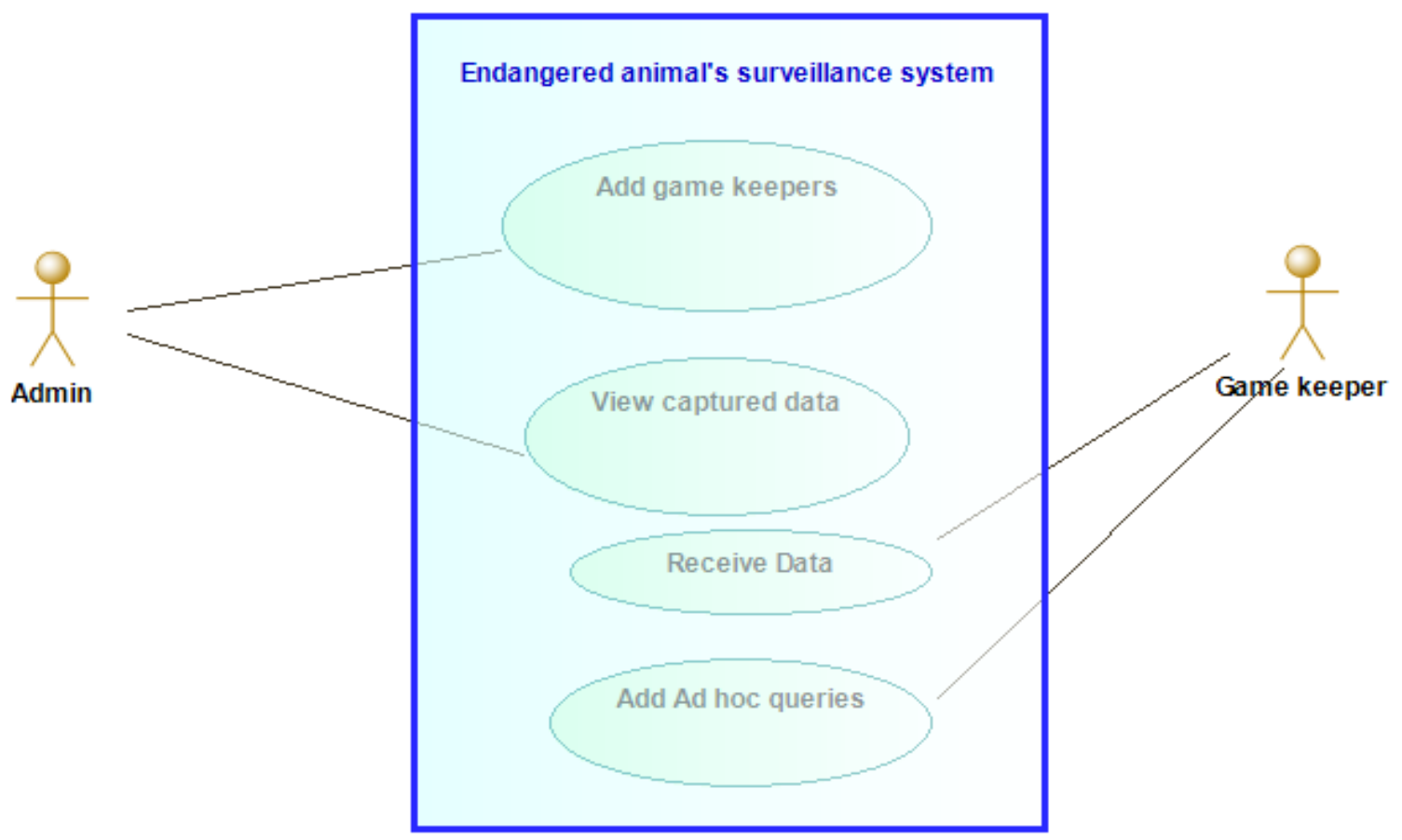

Figure 2: Use case for the endangered animal's surveillance system

\subsubsection{Sequence Diagram}

Sequence diagrams are part of the UML and are used to model the interactions between the actors and the objects within a system. The figure below shows the sequence diagram for the developed endangered animal's surveillance system.

SEQUENCE DIGRAM OF AN ENDANGERED ANIMAL SURVEI LLANCE SYSTEM

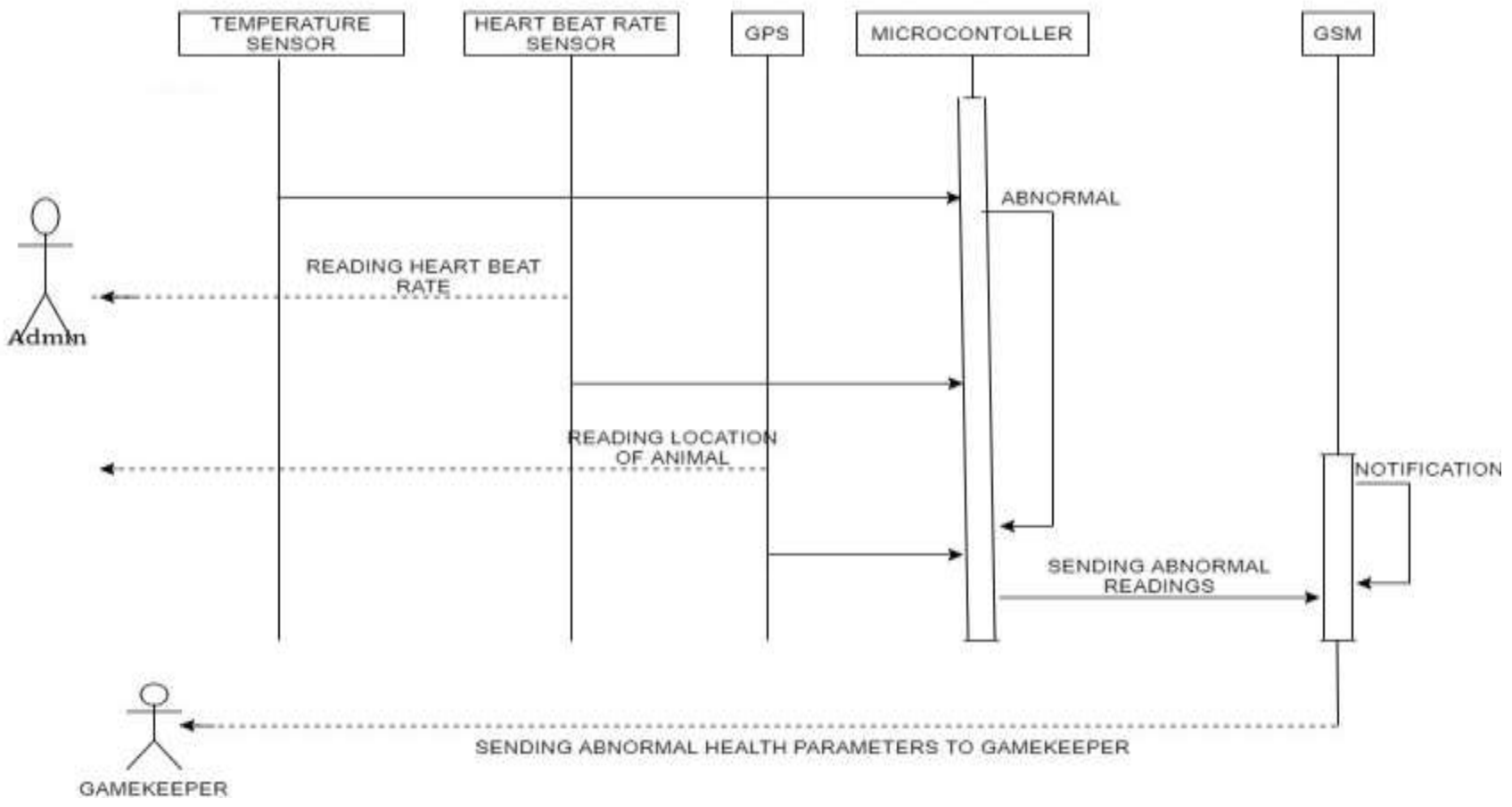

Figure 3 Sequence diagram 


\subsection{The prototype designing}

Dealing with Digital Electronics and Microcontrollers has been one of the most important parts almost in all engineering fields on today's world. With these delicate Components Computer aided design software makes it simple to design systems based on their technology. Computer Simulation helps a designer to see how the devise will work in practical situations before fabricating the Control Circuit. Software like ALTIUM DESIGNER and PROTEUS are popularly used by many Electronic Companies in the World Today. As a part of implementing this research PROTEUS Software was used in Circuit Designing and Circuit Simulation of all the part throughout the whole research. Here below is a circuit diagram designed using PROTEUS Software.

Prototype design involves gathering all the required Components, Properly arranging them on the Vero Board/Circuit Board, fabricating the Circuit by collectively connecting all the Components together and Solder them. Soldering is a process in which two or more metal items are joined together by melting and then flowing a filler metal into the joint - the filler metal having a relatively low melting point. Soldering is used to form a permanent connection between electronic components. The metal to be soldered is heated with a soldering iron and then solder is melted into the connection. After everything done on the circuit board is OK. Power is then fed in the Circuit and Tests are taken. GPS MODULE, GSM MODULE and Temperature Sensor functionality are carefully observed and results are recorded. Finally the Circuit is well cased using Water Proof Box to avoid any mechanical damage and dirtiness.

\section{The circuit design and simulation using Proteus software}

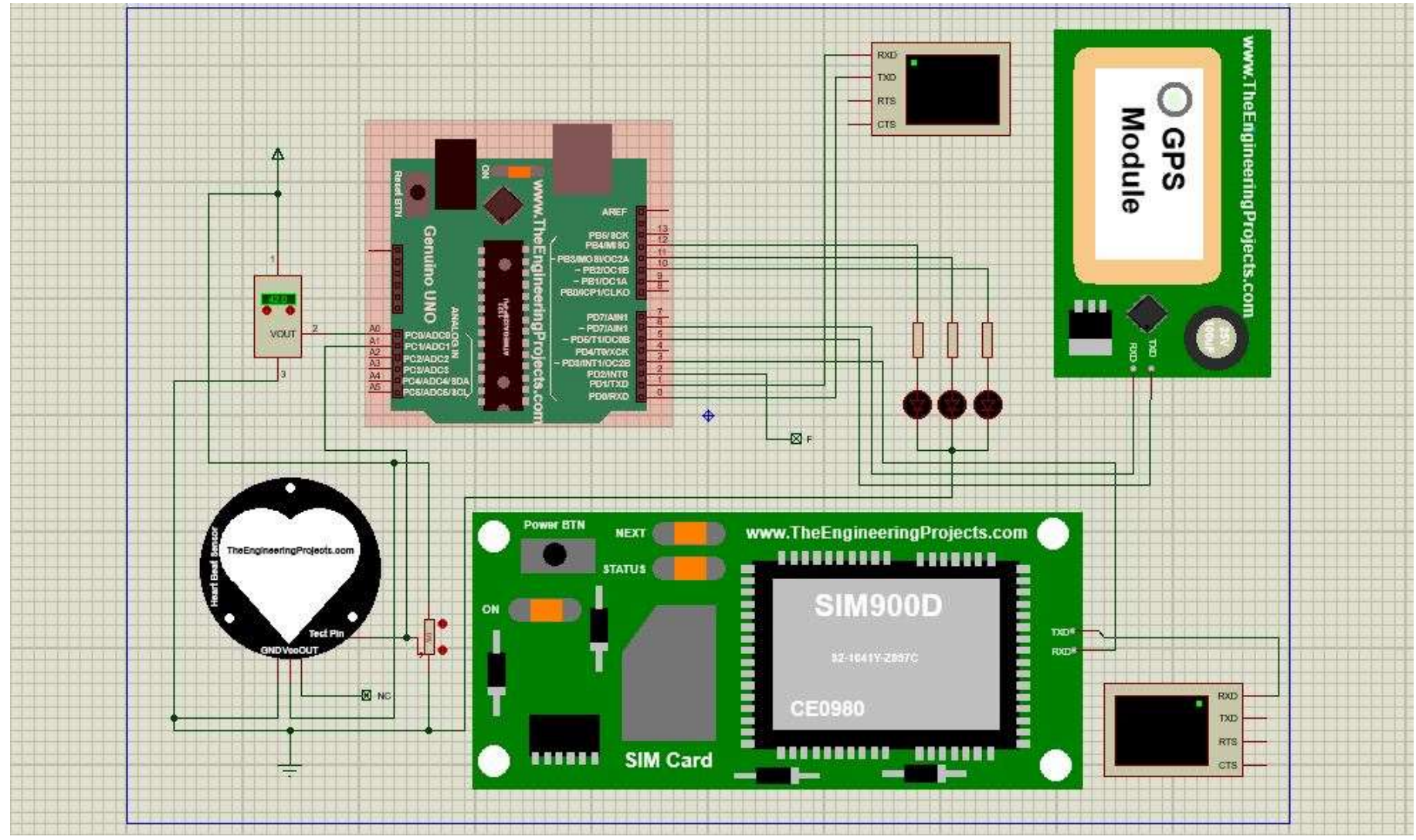

Figure 4: Endangered animal surveillance system: Circuit Diagram

\section{SUMMARY OF RESULTS}

From the data collected at Mikumi National park where ninety two (92) respondents were involved, 69\% of respondents appealed to use physical visit as a means of checking health status of elephants, $12 \%$ confirmed to have no attitude of visiting elephants for health checkup, $49 \%$ reported to be know elephant's health status by observation, $43 \%$ reported to know the health status of elephants after they have been informed by tourists and $36 \%$ of respondents reported to take an average more than three days before knowing if a particular elephant is sick or not. 
International Journal of Engineering Research And Advanced Technology, Vol.5, Issue 7, July-2019

\section{CONCLUSIONS AND RECOMMENDATIONS}

\subsection{Conclusions}

Development, adoption and use of developed system is vital, from the current reported status it is possible that many elephants' mortality is also attributed by diseases though is ignored by many researchers. There is a proof that many elephants are dying by diseases especially at their early ages, Oregon Zoo veterinarian Kelly Flaminio says that about 1 in 5 young Asian elephants dies from the disease in captivity. It's reasonable to suspect that the same number die in the wild. To prevent more elephants from dying having systems providing real time health data is unavoidable.

\subsection{Recommendations}

More researches are to be done on this area to establish quantitative data on the number of elephants dying as a result of diseases outbreaks, appropriate authorities are recommended to start allocating funds to researchers and adopting or enhancing invented integrated systems for a real time animal's health data collections

\section{ACKNOWLEDGMENT}

The author of this research paper acknowledges supports received from the management of the department of Information and Communication Technology, College of Engineering and Technology of Mbeya University of Science and Technology and other comments from reviewers.

\section{REFERENCES}

[1] SeaWorld, "SeaWorld Parks \& Entertainment," SeaWorld Parks \& Entertainment, 2019. [Online]. Available: https://seaworld.org/animals/all-about/elephants/longevity/. [Accessed 0107 2019].

[2] TAWIRI, "PRIORITY AREAS FOR RESEARCH FOR TANZANIA NATIONAL PARKS (TANAPA), NGORONGORO CONSERVATION AREA AUTHORITY (NCAA), WILDLIFE DIVISION (WD) AND TANZANIA FOREST SERVICE (TFS)," TANZANIA WILDLIFE RESEARCH INSTITUTE, Dar es Salaam, 2012.

[3] FAO, "CLINICAL BIOLOGY AND CARE OF THE ELEPHANT," FAO, [Online]. Available: http://www.fao.org/3/v9570e/v9570e03.htm . [Accessed 2705 2019].

[4] J. F. Banzi, "A Sensor Based Anti-Poaching System in Tanzania," International Journal of Scientific and Research Publications, pp. 2250-3153, 2014.

[5] "Frontiers," Frontiers, 2019. [Online]. Available: https://www.frontiersin.org/research-topics/8219/developmentsin-animal-health-surveillance. [Accessed 0107 2019].

[6] OIE, "Guidelines for Wildlife Disease Surveillance:An Overview," OIE, Paris , 2015.

[7] T. Mörner, D. L. Obendorf, . M. Artois and M. H. Woodford , "Surveillance and monitoring of wildlife diseases," Rev. sci. tech. Off. int. Epiz., vol. 21, no. 1, pp. 67-76, 2002.

[8] S. Neethirajan, "Recent advances in wearable sensors for animal health management," Sensing and Bio-Sensing Research, vol. 12, pp. 15-29, 2017.

[9] T. M. Banhazi, H. Lehr, J. L. Black, H. Crabtree, P. Schofield, M. Tscharke and D. Berckmans, "Precision Livestock Farming: An international review of scientific and commercial aspects," Int J Agric \& Biol Eng, vol. 5, 
no. 3, p. $1-9,2012$.

$\begin{array}{ll}\text { ABBREVIATIONS AND ACRONYMS } \\ \text { MUST } & \text { Mbeya University of Science and Technology } \\ \text { SMS's } & \text { Short Message Service } \\ \text { WSNs } & \text { Wireless Sensor Networks. } \\ \text { GPS } & \text { Global Positioning System. } \\ \text { GSM } & \text { Global Service Message. } \\ \text { SMS } & \text { Short Message Service. } \\ \text { SPSS } & \text { Statistical Package for Social Science. } \\ \text { EEHV } & \text { Elephant Endotheliotropic Herpes virus. } \\ \text { TAWIRI } & \text { Tanzania wildlife research institute } \\ \text { FMD } & \text { Foot mouth disease } \\ \text { TANAPA } & \text { Tanzania National Parks } \\ \text { OIE } & \text { The World Organization for Animal Health } \\ \text { WAHIS } & \text { World Animal Health Information System } \\ \text { PLF } & \text { Precision Livestock Farming }\end{array}$

